ISSN: 0213-2087 e-ISSN: 2444-7080

DOI: https://doi.org/10.14201/shhcont3820207797

\title{
JUAN BELMONTE Y LA RENOVACIÓN DE LA MASCULINIDAD NACIONAL
}

\author{
Juan Belmonte and the renewal \\ of national masculinity
}

\author{
David CASTRO DEVESA \\ Universidad París VIII \\ davidcastrodevesa@gmail.com
}

Recibido: 14/02/2020 Aceptado: 20/05/2020

RESUMEN: Este estudio histórico trata de poner de manifiesto la influencia de la corrida de toros en la evolución de la identidad nacional masculina en las primeras décadas del siglo XX. El principal objetivo de esta investigación es analizar las representaciones de la nación y de la masculinidad generadas por los periodistas, pero también por personalidades del mundo de la cultura, a partir de la figura del torero Juan Belmonte. Su exitosa trayectoria profesional y su arriesgada forma de torear fueron asociadas a un renacimiento del espectáculo taurino y por ende, a la regeneración de la virilidad española, reclamada y teorizada por un buen número de intelectuales españoles. La imagen de Belmonte, antitética al estereotipo del torero, y su amistad con un nutrido grupo de escritores y artistas, le convirtieron en la personificación del arquetipo de una masculinidad nacional renovada, civilizada y moderna.

Palabras clave: Corrida de toros; Masculinidades; Identidad nacional; Regeneración; Historia cultural.

ABSTRACT: This historical study tries to show the influence of the bullfight on the evolution of the male national identity in the first decades of the twentieth century. The main objective of this research is to analyze the representations of the nation and masculinity generated by journalists, but also by personalities from the world of culture, based on the figure of bullfighter Juan Belmonte. His successful career and risky way of fighting were associated with a revival of bullfighting and therefore, the regeneration of Spanish manhood, claimed and theorized by a good number of Spanish intellectuals. The image of Belmonte, antithetical to the stereotype of the bullfighter, and his friendship with a large group of 
writers and artists, made him the personification of the archetype of a renewed, civilized and modern national masculinity.

Key words: Bullfight; Masculinities; National Identity; Regeneration; Cultural History.

\section{INTRODUCCIÓN}

La crisis de la nación española a finales del siglo XIX constituye un punto de partida clave para el análisis de la interrelación entre la identidad nacional española y las identidades de género en el seno de la corrida de toros. La derrota militar frente a Estados Unidos en 1898 y la consiguiente pérdida de los territorios de ultramar desencadenaron un cuestionamiento de los fundamentos culturales de la nación ${ }^{1}$, y éste pronto se convirtió en una crisis de la masculinidad ${ }^{2}$. La pérdida de virilidad de la nación española, ese país de "eunucos» como lo describió Joaquín Costa ${ }^{3}$, fue uno de los argumentos utilizados por el movimiento intelectual del Regeneracionismo para explicar la depresión nacional.

Las ansiedades generadas por la crisis de la masculinidad normativa que se produjo en Europa en el último tercio del siglo XIX ${ }^{4}$ se agudizaron en España tras el Desastre del 98. El estado de la raza, medido por las cualidades viriles del pueblo, ocupó un lugar central en el debate sobre el futuro del país 5 . Bajo el prisma de la orientalización ${ }^{6}$, España fue descrita como una nación ajena al progreso y la civilización. Las características de la masculinidad española fueron consideradas inferiores a los rasgos de la masculinidad imperial ${ }^{7}$. Como apunta Nerea Aresti, el torero no representaba en el extranjero un ideal deseable de masculinidad, más bien su antítesis: el hombre salvaje, cruel e irreflexivo ${ }^{8}$.

1. Áldvarez Junco, José: Mater dolorosa. La idea de España en el siglo XIX. Madrid: Taurus, 2001, pp. 584-607; Pan-Montojo, Juan (coord.): Más se perdió en Cuba. España, 1898 y la crisis de fin de siglo. Madrid: Alianza Editorial, 1998.

2. ARESTi, Nerea: "A la nación por la masculinidad. Una mirada de género a la crisis del 98». En: Mary NASH (ed.), Feminidades y masculinidades. Arquetipos y prácticas de género. Madrid: Alianza Editorial, 2014, pp. 47-73.

3. Costa, Joaquín: Los siete criterios de Gobierno, tomo 7. Madrid: Biblioteca Costa, 1914, pp. 176, 222.

4. Martykánová, Darina: «Los pueblos viriles y el yugo del caballero español. La virilidad como problema nacional en el regeneracionismo español (1890s-1910s)", Cuadernos de Historia Contemporánea, 39, 2017, p. 23.

5. Aresti, Nerea y Martykánová, Darina: "Masculinidades, nación y civilización en la España contemporánea: Introducción", Cuadernos de Historia Contemporánea, 39, 2017, p. 13.

6. SAID, Edward: L'orientalisme. L'Orient créé par l'Occident. París: Éditions du Seuil, 2005.

7. Aresti, Nerea y Martykánová, Darina: op. cit., p. 14.

8. Aresti, Nerea: "A la nación por la masculinidad... ", op. cit., pp. 59-60. 
Estos diagnósticos, producidos por autores extranjeros e interiorizados por intelectuales españoles, sumados a la amenaza exterior de un imperialismo beligerante y a la cristalización de los discursos nacionalistas periféricos, principalmente en Cataluña y el País Vasco, acentuaron la percepción de decadencia. La supuesta degeneración de la nación española fue asociada también a la conquista gradual de espacios sociales, tradicionalmente masculinos, por parte de mujeres que transgredían el orden de género establecido, problematizando todavía más la reconstrucción de una virilidad nacional fragilizada tras el Desastre del 989.

El mundo taurino fue también atravesado por la crisis de una identidad viril española que debía reaccionar, por un lado, a la pérdida de los últimos vestigios del Imperio colonial, y que por otro lado, debía hacer frente a una mayor presencia del discurso feminista en la sociedad española y a las mutaciones de las relaciones de género. La ausencia de toreros célebres, la disminución de espectadores en las plazas y la identificación de la fiesta nacional como uno de los males de España por parte de los autores regeneracionistas sumieron también al espectáculo taurino en una profunda crisis tras la retirada del torero Guerrita en $1899^{10}$. La debilidad y cobardía de los toreros modernos simbolizaba, según los cronistas taurinos, el quebranto de la virilidad de todos los españoles. La multiplicación de mujeres en los ruedos a finales del siglo XIX, como prueban los éxitos de la cuadrilla de "las Noyas» o la matadora "la Reverte", suponía una prueba más de la mayor presencia de mujeres en el espacio público haciendo temblar la organización social de la diferencia sexual. Este fenómeno fue interpretado por la prensa como una expresión de los progresos del feminismo en España y como una prueba de la docilidad de los toreros y de los hombres españoles. La evolución de la corrida de toros se convirtió pues, para gran parte del periodismo taurino, en un síntoma de la debilitación del país.

En el mundo taurino, las mujeres poco femeninas, representadas por el estereotipo de la torera, y los hombres poco masculinos, representados por el estereotipo del torero cobarde, se habían convertido en los elementos a eliminar para evitar la feminización de la práctica taurina. Las representaciones peyorativas, producidas principalmente por la prensa taurina, a partir del éxito de las toreras y de los toreros modernos considerados afeminados, eran utilizadas para señalar el estado deplorable de la nación española. La preocupación por los cambios sociales que estaban causando grietas en el ideal burgués de feminidad, debido a los progresos de las mujeres españolas en diferentes sectores profesionales, y la ansiedad ante la posible inversión de los roles de género, desembocaron en la radicalización de los discursos antifeministas. La respuesta a la crisis de las identidades nacionales «generizadas» se plasmó también en los ruedos. En 1908,

9. Cleminson, Richard y Vázquez García, Francisco: 'Los Invisibles': A History of Male Homosexuality in Spain, 1850-1939. Cardiff: University of Wales, 2007, p. 175.

10. Cossío, José María De: Los Toros, tomo 1. Madrid: Espasa-Calpe, 1999 [1943-1961], pp. 182, 189. 
se materializaba la exclusión jurídica de las mujeres de las plazas de toros en España. La discriminación hecha ley buscaba reafirmar la superioridad masculina y mantener el orden de género establecido. En un contexto de crisis de la masculinidad nacional, la tauromaquia fue erigida por la prensa taurina, por el Estado, y también por muchos pensadores y escritores, como una práctica social idónea para seguir generando la virilidad de los futuros jóvenes españoles, ya fuese como actores de la fiesta nacional o como admiradores de los valores de los héroes taurinos.

La prohibición coincidió con una etapa de glorificación del espectáculo taurino gracias principalmente al nacimiento de la rivalidad en los años 1910 entre los toreros José Gómez Ortega (1895-1920), apodado Joselito, y Juan Belmonte García (1892-1962). Su enfrentamiento se convirtió en uno de los temas periodísticos más importantes de la década, hasta el día de la muerte de Joselito en la plaza de Talavera, el 16 de mayo de 1920. En los años 1910, la prensa española, con aproximadamente dos mil títulos ${ }^{11}$, contribuía al desarrollo de la sociedad de masas. Los periódicos de tirada nacional como ABC, El Imparcial o El Heraldo de Madrid, dedicaban una parte importante de sus páginas a las corridas en la sección de espectáculos, en una época en la que los periódicos de mayor difusión podían vender decenas de miles de ejemplares por día ${ }^{12}$. El desarrollo de la prensa se produjo en paralelo al perfeccionamiento del transporte ferroviario y del telégrafo, este último siendo reemplazado gradualmente por el lento desarrollo de la red telefónica en España. Gracias a estos cambios sociales que elevaron la popularidad de los matadores a cotas inimaginables en las décadas precedentes, Belmonte y Joselito realizaron más corridas por año que ningún otro torero en el pasado, toreando cada uno más de 100 por año ${ }^{13}$. Este fenómeno de masas fue acompañado de la construcción masiva de nuevas plazas de toros en ciudades y pueblos ${ }^{14}$, prueba incontestable de la revitalización del espectáculo y del crecimiento del número de aficionados durante este periodo. El duelo taurino, que alcanzó su apogeo durante los años de la Gran Guerra, permitía sublimar la virilidad nacional frente a una neutralidad que ponía de manifiesto la impotencia económica y militar de un país débil y postrado ${ }^{15}$. La etapa de enfrentamiento entre estos toreros, denominada como la Edad de Oro del toreo moderno, significó el final de la crisis para el mundo taurino y la revirilización de la práctica taurina, y por extensión, ésta se convirtió en un símbolo de la regeneración de la virilidad de la propia nación.

11. Navarro Salvador, Eduardo: "Prensa de España». El País, 6 de mayo de 1914, p. 3.

12. Ibid.

13. De la Villa, Antonio: Belmonte: el nuevo arte de torear. Madrid: Talleres Espasa-Calpe, 1928, pp. $232-233$.

14. Pérez De Ayala, Ramón: Política y toros. Madrid: Editorial Calleja, 1918, p. 185.

15. ArChilés, Ferran: «Una nación descamisada: Ortega y Gasset y su idea de España durante la Primera Guerra Mundial (1914-1918)", Rúbrica Contemporánea, 4-8, 2015, pp. 29-47. 
Las representaciones masculinas y nacionales proyectadas por la corrida participaron en la querella sobre la masculinidad nacional. Las representaciones culturales producidas en los discursos sobre la corrida de toros, concebida en este artículo como una metáfora de la propia nación, engendraron repercusiones en el debate y la construcción discursiva de los valores, las normas, los comportamientos, los roles sociales que englobaban la forma de ser un hombre español. Por un lado, los intelectuales socialistas y republicanos consideraron que el espectáculo era responsable de ciertos rasgos negativos de la masculinidad de los hombres españoles como la arrogancia, la agresividad o la chulería. Por el contrario, los periodistas taurinos concibieron la tauromaquia como uno de los medios para mantener y desarrollar las cualidades viriles de los hombres españoles. Varios importantes representantes del Novencentismo defendieron las corridas de toros como una expresión positiva de la masculinidad nacional. En este contexto, la aparición de Belmonte en el mundo de la tauromaquia, que se hizo amigo de escritores, artistas e intelectuales españoles, sirvió para exaltar, a partir del personaje taurino, la masculinidad española.

El objetivo principal de este artículo es demostrar que Juan Belmonte se convirtió en una personificación de la masculinidad nacional. Para ello, nuestro análisis girará en torno a la carrera profesional de este torero, estudiando cómo las representaciones nacionales generizadas presentes en los textos producidos por los periodistas taurinos y por los intelectuales, que le defendieron e incluso le idolatraron, articularon, a partir del cuerpo y la personalidad del torero, el arquetipo de la regeneración de la masculinidad española. Esta investigación trata también de analizar la influencia de este torero, como una de las imágenes masculinas representativas de España, en la formación de discursos de género que sirvieron para consolidar la hegemonía de un cierto modelo masculino en la sociedad española. Ante los males del país, las publicaciones taurinas y la prensa generalista, pero también referentes intelectuales y artísticos, erigieron la práctica taurina en una fuente productora de la virilidad de la raza española que servía de freno a la degeneración nacional. La imagen de Belmonte se transformaba en un ideal masculino capaz de prevenir la supuesta feminización de la sociedad española y en un icono de masas capaz de renovar una masculinidad salvaje y bárbara, asociada tradicionalmente al torero.

Los últimos años han visto multiplicarse el número de publicaciones dedicadas exclusivamente al estudio de la historia de la relación entre género y nación en España ${ }^{16}$. La metodología de esta investigación se basa en la construcción teórica de la relación

16. Andreu, Xavier (ed.): "Género y nación en la España Contemporánea", monográfico de Ayer, 106-2, 2017; AREsti, Nerea, BrÜHne, Julia y Peters, Karin (eds.): ¿La España invertebrada? Masculinidad y nación a comienzos del siglo XX. Granada: Editorial Comares, 2017; ARESTI, Nerea y MARTYKÁNOVÁ, Darina (eds): "Masculinidades, nación y civilización en la España contemporánea», monográfico de Cuadernos de Historia Contemporánea, 39, 2017. 
entre género y nación realizada por Nira Yuval-Davis y Floya Anthias ${ }^{17}$, y luego desarrollada por Yuval-Davis en su libro Gender and Nation. En este sentido, este estudio histórico aborda pues la tauromaquia como un fenómeno cultural que produce representaciones nacionales y de género, desde la prensa y la literatura, participando en la construcción social de los roles de género y de la estructuración de las relaciones de género en la sociedad española en el primer tercio del siglo XX.

Se trata, en definitiva, de entender el mundo taurino como un laboratorio en el que explorar, a una escala reducida, los cambios producidos en torno a las identidades nacionales y de género. Para poder examinar mejor la relación entre el toreo, la nación y la masculinidad, este artículo toma como punto de referencia la trayectoria taurina del torero Juan Belmonte. Este análisis intenta contribuir a una mejor comprensión de los mecanismos que rigen la elaboración discursiva de las identidades nacionales generizadas y a un mayor entendimiento de la manera en que éstas se encarnan en manifestaciones culturales concretas.

\section{EL TORERO Y LOS INTELECTUALES}

Juan Belmonte, nacido en 1892 en Sevilla, en una familia muy pobre, se convirtió en un ídolo de masas pero también «en un señorito educado, que le admiran no sólo los públicos, sino hombres que se llaman intelectuales y que figuran en los altos puestos de la política» ${ }^{18}$. En 1909, con tan solo 17 años y sin haber recibido todavía la alternativa, Julio Romero de Torres (1874-1930) pintaba ya su retrato con dedicatoria incluida: «al gran novillero Juanito Belmonte en prueba de nuestra amistad „19. Belmonte comenzó a rodearse de un grupo de intelectuales entre los que se encontraban el propio Romero de Torres, los escultores Sebastián Miranda (1885-1975) y Julio Antonio (1889-1919), los poetas Enrique de Mesa (1878-1929) y Luis de Tapia (1871-1937), los escritores Julio Camba (1884-1962), Ramón del Valle-Inclán (1862-1936) y Ramón Pérez de Ayala (1880-1962) ${ }^{20}$ (Figura n ${ }^{\circ}$ 1).

Lo cierto es que éstos y otros personajes del mundo de la cultura entablarían amistad con el torero y le acompañarían durante toda su trayectoria profesional. En 1913, tras la celebración de sus primeras corridas en Madrid, un nutrido grupo de periodistas, escritores y artistas, admiradores del torero, ofrecieron un banquete en su honor. El encuentro tuvo lugar en un restaurante en los Jardines del Retiro (Figura $n^{\circ} 2$ ).

17. Anthias, Floya y Yuval-Davis, Nira: "Introduction». En: Anthias, Floya y Yuval-Davis, Nira (eds.): Women-Nation-State. London: Macmillan, 1989, pp. 1-15.

18. Nuño de la Rosa, José: "Belmonte, o la fuerza de una voluntad». La Lidia, 17 de diciembre de 1917 , p. 5.

19. Romero de Torres, Julio: Belmonte novillero. 1909. En: http://www.eldiadecordoba.es/ocio/ Belmonte-novillero-Romero-Torres-Madrid_0_170383242.html, consultado el 30 de diciembre de 2019.

20. Alonso, J. M.: "Aquel banquete de los escritores y los artistas a Juan Belmonte», El Ruedo, 18 de julio de 1945, p. 17. 


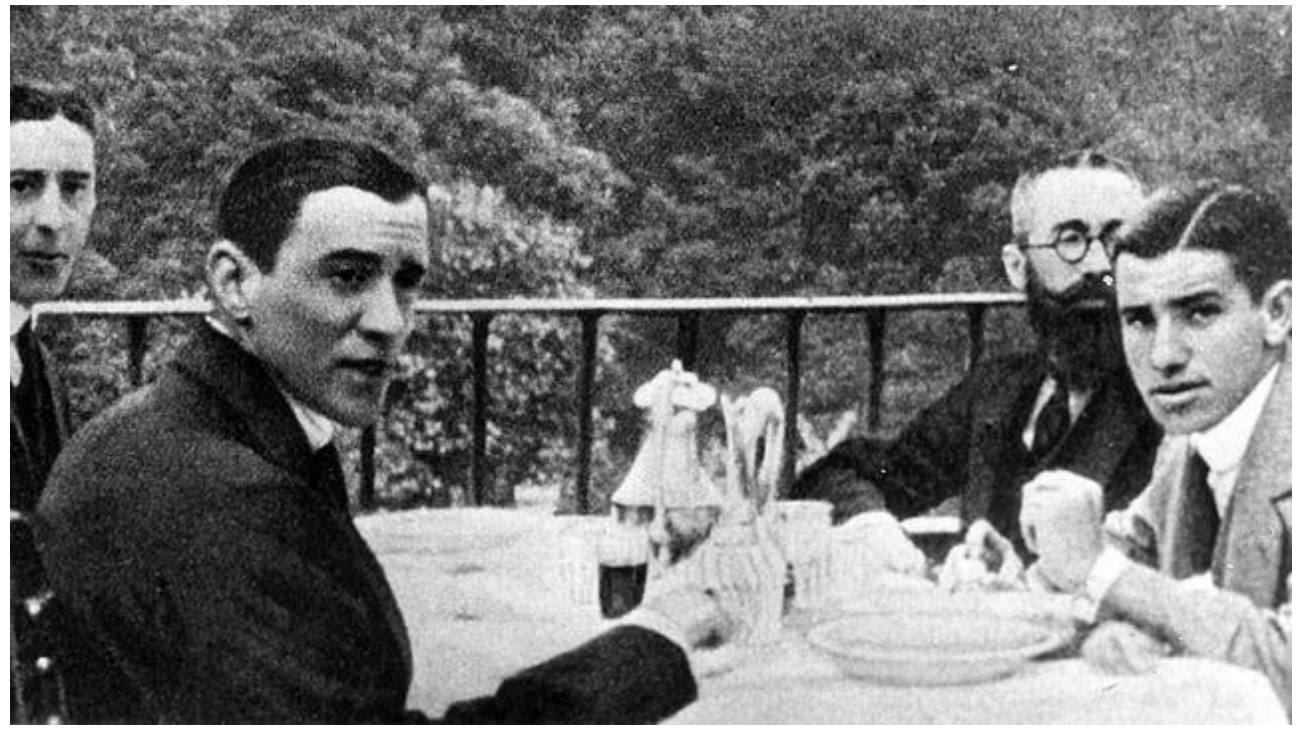

Figura $n^{\circ}$ 1: Belmonte en el estudio de Sebastián Miranda, con Pérez de Ayala y Valle-Inclán²1.

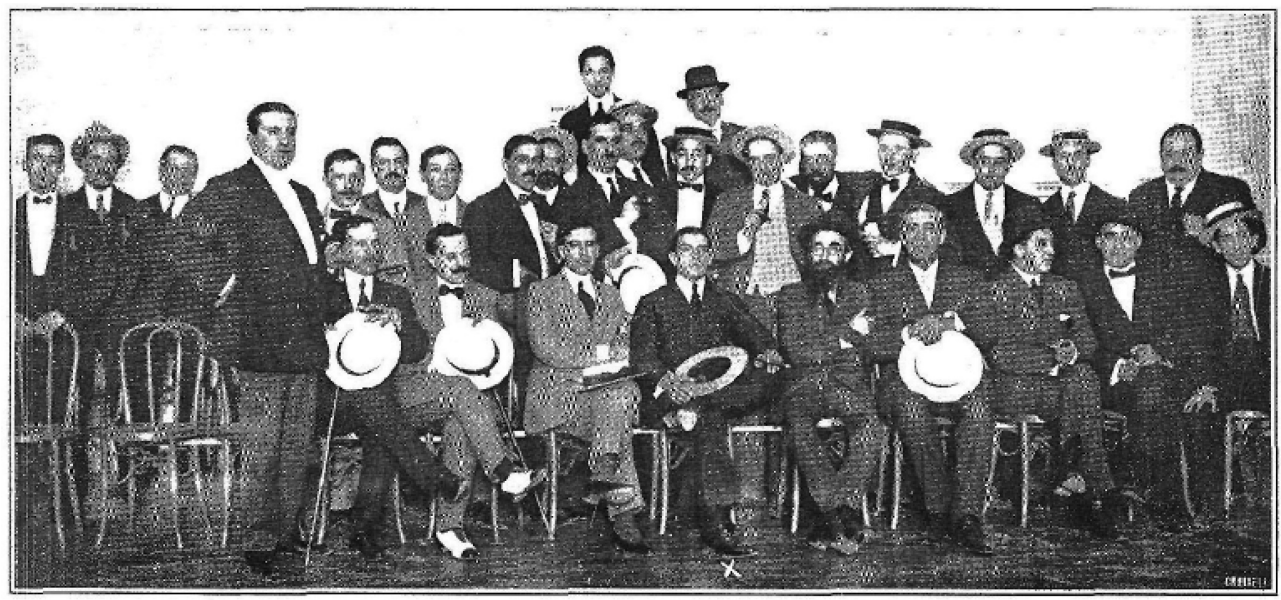

Figura $n^{\circ}$ 2: El banquete ${ }^{22}$.

21. ABC, 27 de enero de 2014. En: http://www.abc.es/cultura/toros/20140127/abci-juan-belmonteproezas-hombre-201401262134.html, consultado el 30 de diciembre de 2019.

22. Unión Ilustrada, 13 de julio de 1913, p. 22. 
Valle-Inclán, uno de los pocos miembros de la Generación del 98 que defendió la Fiesta Nacional, admiraba la transformación de Belmonte en los ruedos:

Yo en Belmonte, por ejemplo, admiro el tránsito. Aquel hombre que lejos del toro es feo, pequeño, ridículo, encogido, sin belleza, al reunirse con el toro se transfigura y nos parece maravilloso, y nos arrastra y nos emociona. Ese es el arte en las corridas de toros ${ }^{23}$.

En la misma entrevista, realizada por la revista taurina Palmas y Pitos en 1915, el dramaturgo criticaba «esa campaña que los escritores cursis han hecho contra las corridas de toros" y se quejaba amargamente de los cambios sociales acaecidos en España "porque éramos un país fuerte» pero ahora «lloramos como mujeres» ante la muerte de un torero en la plaza o de un teniente en la guerra ${ }^{24}$. Pérez de Ayala, fiel admirador de Belmonte, describía al torero con estos calificativos: «encantador», "prudente», "muy inteligente» $\mathrm{y}$ "perspicaz»" 25 . Para el escritor español, Belmonte había purificado y depurado la práctica del toreo para eliminar de ella los rasgos más desagradables hasta el punto que sus corridas eran también festejadas por los extranjeros:

Pero había que tener fe en el santo advenimiento y aguardar la llegada del Mesías, que cancelase la antigua ley de crueldad y barbarie (imperante en la vieja tauromaquia) y promulgase la nueva ley de gracia. Por eso, como español, y animado por esa fe mesiánicoartístico-tauromáquica, era yo aficionado a las corridas de toros, aun reconociendo-mas no reprobando—su misteriosa bestialidad y vitalidad elementales ${ }^{26}$.

El discurso de Pérez de Ayala en defensa de las corridas de toros era característico de la Generación de 1914 ya que como afirmaba José María de Cossío, sus autores eran capaces de defender el espectáculo, y el carácter español de éste, sabiendo al mismo tiempo identificar sus defectos ${ }^{27}$. El médico Gregorio Marañón (1887-1960) mantuvo también una gran amistad con el torero y fue un confeso partidario de Belmonte ${ }^{28}$. Marañón, que contribuyó de manera muy importante a desarrollar las bases científicas de un esencialismo biologizante de la condición masculina y femenina, consideraba la práctica deportiva como una actividad viril que permitía desarrollar la virilidad de los cuerpos masculinos y que debía ser evitada por las mujeres ${ }^{29}$. El pintor español Ignacio Zuloaga (1870-1945) también fue un gran amigo del torero. Lo representó en

23. Don Pepe: «Valle Inclán y los toros». Palmas y pitos, 29 de marzo de 1915, pp. 3-4.

24. Ibid.

25. Citado en: Cambria, Rosario: Los toros: tema polémico en el ensayo español del siglo XX. Madrid: Gredos, 1974, p. 117.

26. Citado en: De la Villa, Antonio: op. cit., p. 429.

27. CAmbria, Rosario: op. cit., pp. 176-177.

28. Cambria, Rosario: op. cit., pp. 155, 159.

29. MARAÑón, Gregorio: Ensayos sobre la vida sexual, en Alfredo Juderías, Obras completas, vol. VIII, Recopilación de Juderías, Alfredo. Madrid: Espasa-Calpe, 1972, p. 337. 
dos de sus cuadros, el primero titulado Belmonte en plata ${ }^{30}$ y un segundo que no pudo terminar, titulado Mis amigos ${ }^{31}$. En este último, podemos observar la representación de los amigos de Zuloaga, pertenecientes a las élites culturales e intelectuales de las primeras décadas del siglo XX, donde también aparece Juan Belmonte. La figura del torero aparece rodeada de sus defensores, como José Ortega y Gasset, Ramón del ValleInclán o Gregorio Marañón, y críticos de las corridas de toros, como Pío Baroja o Miguel de Unamuno. No hay duda: el torero Juan Belmonte fue una figura eminentemente importante en la sociedad española en el primer tercio del siglo XX.

La amistad de Belmonte con esta nueva generación de intelectuales, escritores y artistas fue uno de los factores importantes que propulsaron un cambio en la percepción de la corrida de toros, mitigando de esta manera el ascenso del discurso antitaurino en los círculos intelectuales de la sociedad española. Si para gran parte de los autores regeneracionistas, la corrida de toros representaba uno de los males de España, los novecentistas dibujaron de nuevo un retrato positivo, algunos tímidamente y otros con gran vehemencia como lo hizo José Ortega y Gasset, de la fiesta nacional como símbolo de la masculinidad española. Y en este proceso fueron claves las características de Belmonte dentro y fuera de los ruedos.

\section{LA ANTÍTESIS DEL TORERO}

La existencia de Belmonte, un hombre que, fuera de las plazas, prefería reunirse con escritores y artistas antes que seguir hablando de toros, permitía a ciertos sectores de la sociedad española poder reafirmar al torero como la personificación masculina de la españolidad. Muchas crónicas resaltaban lo poco que Belmonte se acercaba al estereotipo de torero. Tras pasar unas horas en la casa de Belmonte, el periodista y escritor Wenceslao Fernández Flórez escribía irónicamente en las páginas del $A B C$ : "Tú no eres un torero» ${ }^{32}$. La ausencia de cabezas de toro en los muros, la presencia de libros de escritores como Anatole France y el hecho de que las personas que visitaban al matador fueran «artistas, hombres de cultura, de valer» y no «toreros, ni 'cantaores', ni duques, ni marqueses, ninguna, en fin, de esas figuras que bullen alrededor de los diestros», hacían de Belmonte un hombre alejado de los rasgos arquetípicos de los toreros. El propio Belmonte afirmaba: «Soy muy aficionado a leer; las emociones de mi profesión las alterno con las de la lectura»33. En El Globo, Federico Gónzalez-Rigabert

30. Zuloaga, Ignacio: Belmonte en plata. Zumaia: Museo Zuloaga, 1924. En: http://instatterminus. blogspot.com.es/2011/11/medina-sidonia-y-los-toros.html, consultado el 29 de diciembre de 2019.

31. ZuloagA, Ignacio: Mis amigos. Zumaia: Museo Zuloaga, 1920-1936. En: http://www.diariovasco. com/v/20100310/cultura/amigos-zuloaga-salen-zumaia-20100310.html, consultado el 29 de diciembre de 2019.

32. Fernández Flórez, Wenceslao: «Terremoto no está». ABC, 30 de abril de 1917, p. 9.

33. $A B C, 1$ de junio de 1915, p. 10. 
destacaba cómo la adquisición por parte del torero de un cuadro de Julio Romero de Torres, estimado en cinco mil pesetas, había hecho cambiar su opinión sobre Belmonte: "la indiferencia nuestra hacia el torero de moda -indiferencia nacida de un prudente antitaurofilismo- hase convertido en admiración cuando hemos tenido noticia de esa su mejor faena ${ }^{34}$. El escritor Ramón Gómez de la Serna resaltaba el apoyo que el torero ofrecía a los intelectuales en España: «¡Oh esperanza paradójica y pintoresca en el país inhóspito para los escritores la de que los toreros puedan ser hasta los propulsores de un Renacimiento!, 35 .

Si el comportamiento de Belmonte fuera de las plazas podía provocar la fascinación de parte de los no aficionados al espectáculo taurino, éste suscitaba a su vez las suspicacias de parte de los acérrimos apasionados a los toros que no perdían ocasión de criticar la "cursilería intelectual en que sus amigos han envuelto a Belmonte»: "Creemos que un torero está bien hablando de toros, de mujeres, de vino, de cante flamenco, de cortijos y de cacerías; pero nos revienta hablando de comedias o de novelas» ${ }^{36}$. En este sentido, el periodista José María Carretero Novillo, en su reportaje sobre el torero en la revista Nuevo Mundo, explicaba de esta manera las razones por las que no podía declararse defensor de Belmonte:

El torero ha sido y es un símbolo genuinamente español. En torno de su figura hay toda una leyenda y también todo un arte pictórico y literario. Y como esto, para un pueblo, tiene siempre un valor, hay que conservarlo tal como es, con su aureola de bizarría y de destreza; con sus matices de flamenquería; con sus alardes de pintoresquismo. El torero, ese mozo audaz y corajudo, ídolo plebeyo, gladiador envuelto en sedas y oro, tiene una leyenda castiza, bárbara, sangrienta y pintoresca. [...] Usted es bravo y simpático e inteligente. Y además, torero. Pues a serlo, con todas sus consecuencias ${ }^{37}$.

Los intereses, las actividades, los comportamientos y las amistades de Belmonte no se adaptaban a la imagen que muchos periodistas taurinos tenían sobre el estereotipo normativo del torero. Una de las polémicas que Belmonte protagonizó tuvo lugar cuando éste decidió cortarse definitivamente la coleta, elemento distintivo del torero en activo, tras realizar su servicio militar como soldado de cuota durante tres meses. La publicación satírica The Kon Leche aprovechó este suceso para criticar el estilo de vida del torero en un artículo titulado "Las reformas de Juanito» acompañado de una caricatura (Figura $n^{\circ} 3$ ):

Ya saben ustedes que Juan Belmonte es un 'pollo litri' que contonea su figura 'británica' por las calles con una elegancia abrumadora... Por teatros, conciertos y 'thes'

34. Gónzalez-Rigabert, F.: «La mejor faena». El Globo, 10 de mayo de 1915, p. 1.

35. Citado en: De la Villa, Antonio: op. cit., pp. 366-367.

36. "Belmonte "intelectual'". The Kon Leche, 3 de Agosto de 1914, p. 7.

37. El Caballero Audaz, "La figura de la semana: Juan Belmonte». Nuevo Mundo, 15 de abril de 1921, p. 10. 
tangos, vemos al fenómeno 'flanearse' ni más ni menos que el más atildado 'sportmant' de London. Del Palace-Hotel al Ideal-Room... de ahí no baja un peldaño el archielegantísimo fenómeno. [...] Bien está que se vista de 'smokin' para ir al Ideal-Room, ó de Carmelita descalzo... para ir a los bailes de la Zarzuela. Pero a la plaza hay que ir de torero iqué diablo! Y el torero requiere traje de luces, montera, coleta, moña y todos los aditamentos que la tradición exige en esta fiesta genuinamente española... ${ }^{38}$.

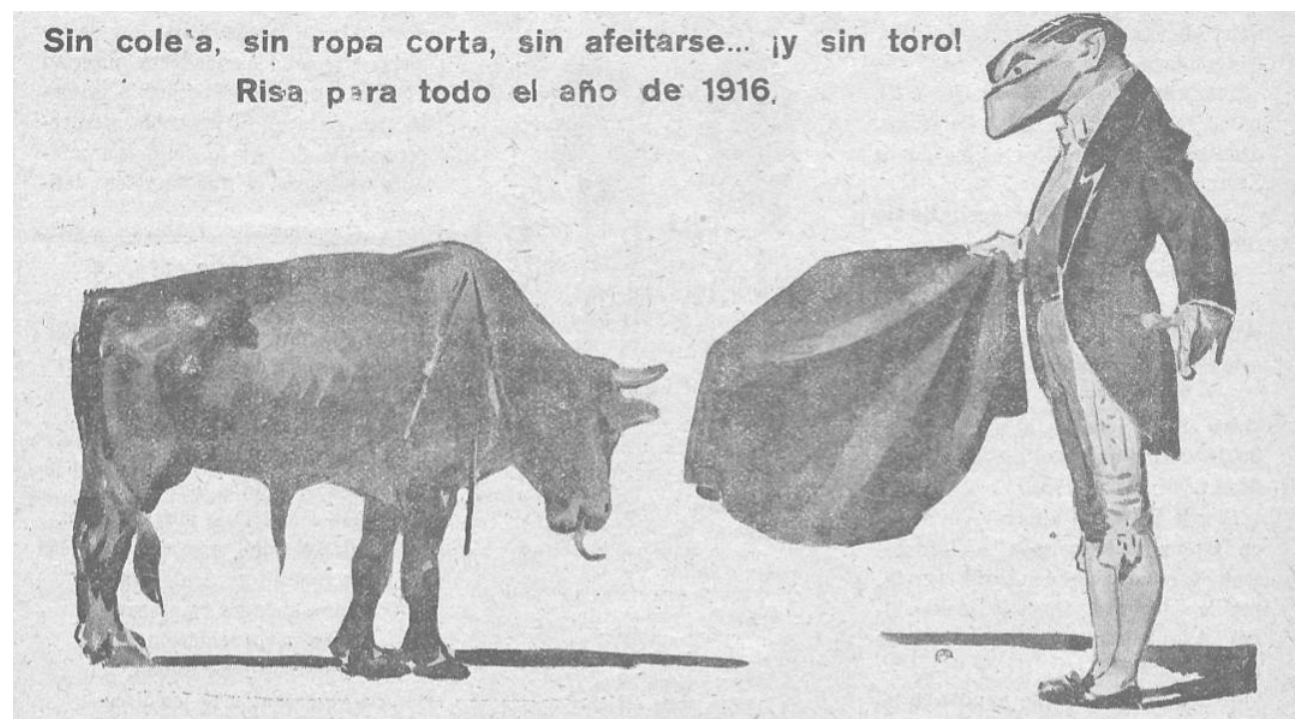

Figura $n^{\circ}$ 3: Belmonte sin coleta ${ }^{39}$.

La proximidad de este torero al modelo masculino del gentleman inglés, un referente cultural que influenció enormemente a las élites españolas en las primeras décadas del siglo $\mathrm{XX}^{40}$, provocaba un fuerte rechazo en los defensores de las tradiciones taurinas, que le acusaban de no representar al auténtico torero español. Sin embargo, el rechazo de Belmonte a "ciertos elementos decorativos y exóticos de la profesión» no le impedía ser considerado como «uno de los más legítimos orgullos de la raza» ${ }^{41}$.

En 1921, diferentes reportajes fotográficos (documento n4) proyectaban la imagen de Belmonte como «un buen padre de familia en la intimidad de su hogar burgués

38. "Las reformas de Juanito". The Kon Leche, 13 de diciembre de 1915, pp. 5-6.

39. The Kon Leche, 13 de diciembre de 1915, p. 5.

40. Martínez del CAMPo, Luis: "La educación del gentleman español. La influencia británica sobre la elite social española (1898-1936)", Ayer, 89, 2013, pp. 131-132.

41. Alcazar, Federico M.: «Belmonte se va!». Nuevo Mundo, 14 de julio de 1922, p. 31. 
y confortable, donde a las clásicas cabezas de toro disecadas han substituido obras de nuestros mejores artistas... ${ }^{42}$. Pese a su rotundo éxito, las publicaciones taurinas caracterizaban al torero como un hombre muy humilde ${ }^{43}$, capaz de rechazar actos de homenaje para huir de la idolatría ${ }^{44}$. En 1921, tras anunciar que abandonaba los ruedos, el periódico $L a$ Voz señalaba que Belmonte «se ha retirado de su profesión calladamente, modestamente, como es él: sin explotar su retirada con múltiples despedidas» ${ }^{45}$.
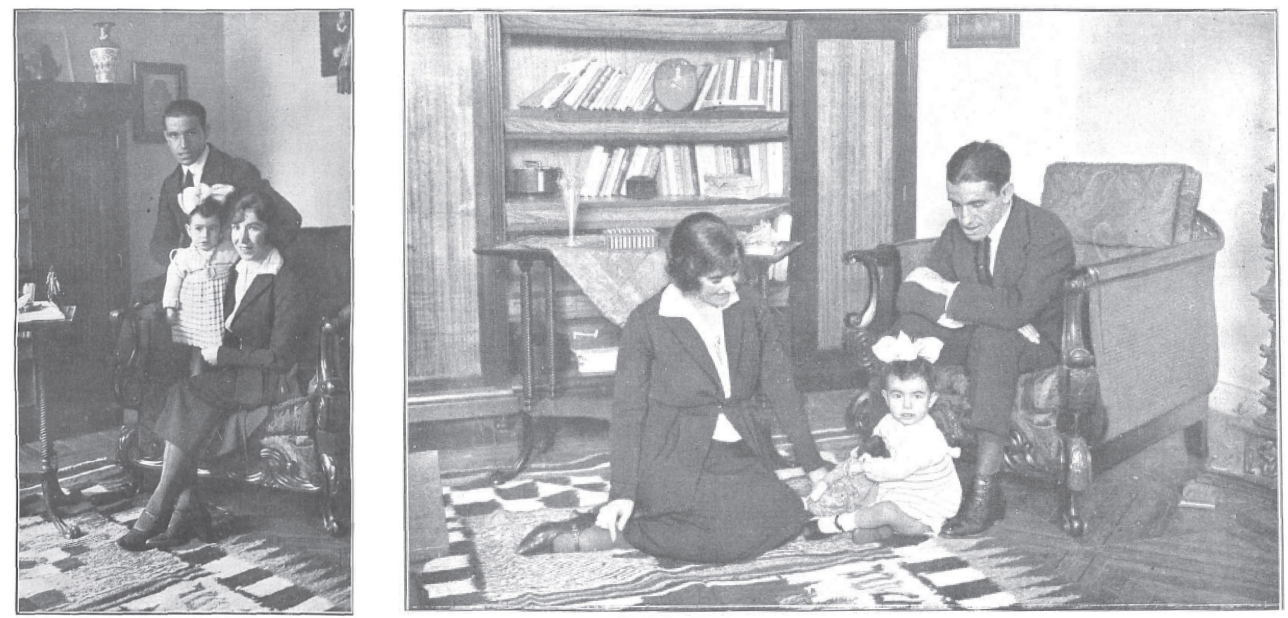

Figura $n^{\circ}$ 4: Belmonte y su familia ${ }^{46}$.

El prototipo de hombre representado por Belmonte se ajustaba a la construcción de una masculinidad española regenerada, antitética a la irresponsabilidad y la inmoralidad de la figura de Don Juan, articulada por los discursos médicos de la época: un hombre trabajador, austero, sereno, instruido, un padre y un marido responsable ${ }^{47}$. Belmonte representaba un modelo social que servía de espejo al pueblo, como afirmaba el escritor Cristóbal de Castro (1874-1953), «más indiferente de Europa»:

Belmonte, que ante la desidia española, es un claro y límpido ejemplo de responsabilidad, de solvencia, de hidalguía profesional. [...] No sólo es el torero fino y sabio en

42. Nuevo Mundo, 15 de abril de1921, p. 11.

43. El Toreo, 23 de marzo de 1914, pp. 1-2.

44. $A B C, 26$ de noviembre de 1915, p. 21.

45. V.B., "Juan Belmonte se ha retirado de los toros". La Voz, 14 de septiembre de 1922, p. 8.

46. Nuevo Mundo, 15 de abril de 1921, p. 11; Mundo Gráfico, 13 de abril de 1921, p. 15.

47. AREsti, Nerea: "Masculinidad y nación en la España de los años 1920 y 1930", Mélanges de Casa Velazquez, 42-2, 2012, p. 61. 
el tiempo de los toreros bastos y torpes, sino el profesional pundonoroso en el país de los profesionales mixtificadores, haraganes y chapuceros... ${ }^{48}$.

Su figura era tan admirada porque el hombre que se escondía tras el traje de luces se aproximaba al modelo masculino reclamado por los reformadores laicos. Podemos afirmar que Belmonte participó en la renovación de la masculinidad nacional, adaptando el héroe taurino a la modernidad y representando un modelo masculino en el que gran parte de las élites culturales identificaba al hombre capaz de regenerar la nación.

\section{UN ICONO VIRIL CONVERTIDO EN HÉROE NACIONAL}

Si al comienzo de su carrera, el cuerpo de Belmonte representaba un objeto de mofa $^{49}$ para los periodistas taurinos ya que no poseía las cualidades físicas idóneas para poder ejercer la profesión, el torero se transformó progresivamente en el prototipo de atleta. Las críticas al estado físico de Belmonte fueron utilizadas también por intelectuales antitaurinos como Eugenio Noel (1885-1936) o Ángel Samblancat Salanova (1885-1963). Este último, abogado, periodista y cofundador del Bloc Republicà Autonomista en 1915, que describía al torero sevillano como «jorobado, tartamudo, patizambo y prognato", manifestaba que «el pueblo que se extasía ante las caras de mono y de salvaje de los toreros, tiene que ser un pueblo de monos y de salvajes ${ }^{50}$. El periodista Mariano de Cavia refutaba estas afirmaciones utilizando la amistad del torero con aquellos «que forman hoy la nata y flor de la literatura actual» ya que le resultaba difícil «incluir en el referido 'pueblo de monos y salvajes' a Valle Inclán, Pérez de Ayala, Luis de Tapia, García Sanchíz y otros muchos „51.

En el momento álgido de su carrera, el periodista José Nuño de la Rosa ya señalaba que "su inquebrantable voluntad le lleva por camino seguro de hacerle un atleta". La prensa taurina se hacía eco también de la "gran resistencia física " 52 demostrada por Belmonte en partidas de caza realizadas junto a periodistas y escritores. La revista Gran Vida, en un artículo acompañado de una fotografía en la que podemos ver a Luis de Tapia y Belmonte tras haber jugado un partido de tenis, subrayaba positivamente la actividad física del torero realizada fuera de los ruedos: "no cabe duda que Belmonte siente amor por los ejercicios al aire libre y comparte las sanas doctrinas de los higienistas modernos ${ }^{53}$. Tras su primera retirada, Belmonte retornaba a los ruedos en 1926

\footnotetext{
48. Citado en: De la Villa, Antonio: op. cit., pp. 359-361.

49. El Duende, 29 de marzo de 1913, p. 12.

50. Citado en: Sobaquillo: "Lo de fuera y lo de dentro». La Lidia, 4 de agosto de 1914, pp. 2-3.

51. Sobaquilo: "Lo de fuera y lo de dentro». La Lidia, 4 de agosto de 1914, pp. 2-3.

52. Castro, V.: "Cacerías en el alto Aragón", Gran vida, noviembre de 1914, p. 325.

53. "Los artistas y el tennis", Gran vida, 1 de septiembre 1922, p. 10.
} 
en Jerez de la Frontera y la revista Mundo Gráfico acompañaba esta noticia con esta «admirable fotografía» (Figura $n^{\circ} 5$ ).

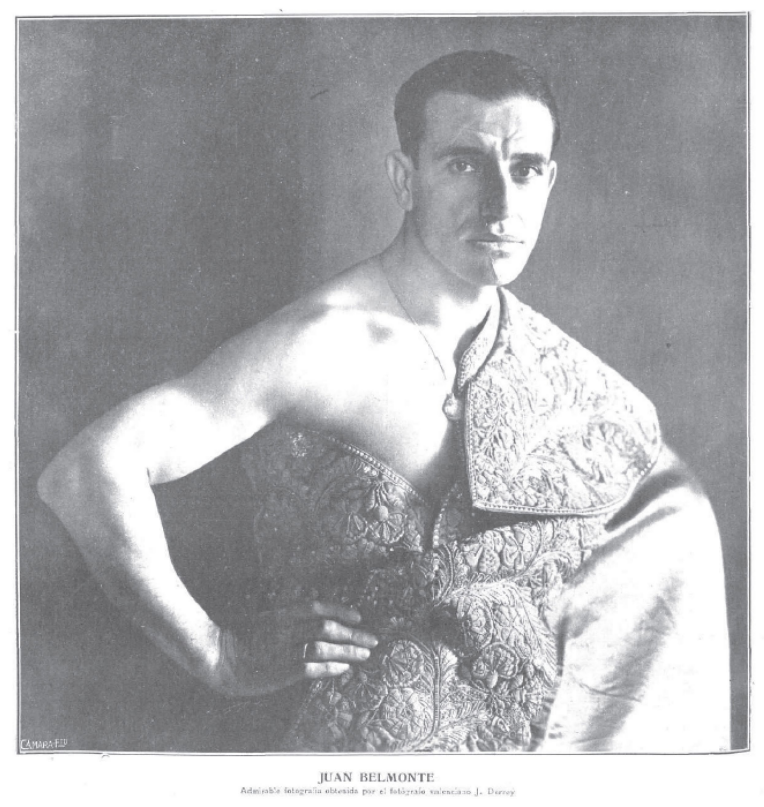

Figura $n^{\circ}$ 5: El cuerpo de Belmonte ${ }^{54}$.

Si Belmonte se transformó en un representante de la regenerada virilidad nacional, fue principalmente gracias a su particular y única manera de torear, en la que resaltaba sobremanera su valentía frente al toro. El periodista César Jalón (1889-1985) afirmaba que "nadie ha toreado tan cerca " 55 . El estilo de Belmonte suponía un constante desafío a la muerte, «la reminiscencia de una raza viril» 56 . La innovación del toreo de Belmonte trajo consigo, según los periodistas taurinos, "el resurgimiento, la regeneración de una fiesta que era monótona, fría, ${ }^{57}$ desterrando así al estereotipo del torero afeminado: "encogido o despatarrado, presto al salto o a la huida, en esa actitud torpe, miedosa, desairada y fea ${ }^{58}$. A pesar de que su gran rival Joselito era reconocido por su técnica

54. Mundo Gráfico, 21 de abril de 1926, p. 12.

55. Citado en: De la Villa, Antonio: op. cit., p. 398.

56. Nuño de la Rosa, José: "Belmonte, ó la fuerza de una voluntad". La Lidia, 17 de diciembre de 1917 , p. 5.

57. Anasagasti, Victorio de: El secreto de Belmonte, Madrid, Artística de Sáenz Hermanos, 1915, pp. 9, 11, 42, 43 .

58. Citado en: De la Villa, Antonio: op. cit., p. 423. 
y su control de las reglas clásicas del toreo, Belmonte revolucionó el mundo de la tauromaquia introduciendo una forma original de torear que se distinguía sobre todo por esquivar la embestida del animal lo más tarde posible. Y era este coraje frente al peligro, el que provocaba una mayor admiración hacia Belmonte que hacia Joselito entre las clases populares ${ }^{59}$ pero también entre los intelectuales. Valle-Inclán lo resumía de esta manera:

El torero que toreando se acerque más a la muerte, ese será el mayor artista, el que mejor interpretará la tragedia taurina, aunque el otro, el que toree con mayor facilidad, quede más veces mejor que él ${ }^{60}$.

He aquí la verdadera esencia de la corrida. En realidad, «la hermosa fiesta de terror y de alegría” como la describía el poeta Manuel Machado (1874-1947), puede definirse como una tragicomedia en la que la tragedia es la muerte del torero y la comedia la muerte del toro. Y cuánto mayor sea el peligro para el héroe, y más cerca esté la tragedia, más loable es la hazaña y más festivo el espectáculo. Gerardo Diego (1896-1987), poeta de la Generación del 27, dedicó al torero un poema titulado «Oda a Belmonte» en el que elogiaba su virilidad: "Yo canto al varón pleno, / Al triunfador del mundo y de sí mismo / Que al borde -un día y otro- del abismo / Supo asomarse impávido y sereno" ${ }^{61}$. La gloria de Belmonte evocaba a la imagen triunfante del soldado victorioso, la personificación nacional del arquetipo masculino encargado de regenerar al país.

La atracción del pueblo por Belmonte elevó su figura a la condición de mito, «una especie de Rodrigo Díaz de Vivar" ${ }^{62}$ : "Alá era grande hasta que ha venido Belmonte a decirle: ¡Regular, solamente regular!» ${ }^{63}$. Federico García Sanchiz explicitaba de esta manera el proceso de mitificación: «Juan ya no es Juan. [...] Al lado del espada de carne y hueso camina otro lidiador creado por España entera, soñado, mítico»64. Belmonte se transformó en un verdadero ídolo de masas ${ }^{65}$, una "superstar» ${ }^{66}$ como lo describe Adrian Shubert. En 1921, tras el trauma nacional de Annual, Belmonte participó en las denominadas Corridas Patrióticas ${ }^{67}$, organizadas en Madrid y Barcelona, para sostener financieramente los cuidados de todos los soldados españoles heridos en la batalla.

59. Pérez de Ayala, Ramón: op. cit., pp. 247-248.

60. Rivera Ballester, José: «iAl fin... realidad!». Palmas y Pitos, 14 de junio de 1915, p. 4.

61. Diego, Gerardo: Poesías y prosas taurinas. Valencia: Pre-textos, 1996, p. 61.

62. $A B C, 11$ de octubre de 1915, p. 12.

63. "Todo Belmontiano", $A B C, 16$ de octubre de 1913, p. 6.

64. García Sanchiz, Federico: "Belmonte o la fuerza del sino". $A B C, 14$ de abril de 1914, p. 4.

65. Zamacois, Eduardo: «Un rato a toros». Mundo gráfico, 12 de mayo de 1915, p. 4; El Caballero Audaz: "La figura de la semana: Juan Belmonte». Nuevo Mundo, 15 de abril de 1921, p. 10.

66. SHubert, Adrian: A las cinco de la tarde. Una historia social del toreo. Madrid: Turner, 2002 [1999], p. 76.

67. El Imparcial, 27 de septiembre de 1921, p. 7; La Voz, 26 de septiembre de 1921, p. 4. 
Las plazas repletas de símbolos nacionales y de emblemas militares, presididas por las más altas autoridades (los Reyes asistieron a la Corrida Patriótica celebrada en Madrid), y la escenificación del espectáculo taurino, que se inició con la reproducción de $L a$ canción del soldado, ponen de manifiesto que estos rituales taurinos buscaban exaltar el sentimiento nacional entre las masas en un momento histórico en el que el prestigio de la nación española había quedado en entredicho por un nuevo fracaso de su campaña imperialista en África del Norte.

Todo lo relevante al torero suscitaba mucha atención, como lo demuestran los numerosos artículos dedicados a su boda en América y a la descripción de su esposa ${ }^{68}$, Julia Cossío Pomar, pero también el propio recibimiento del diestro en el puerto de Cádiz a su vuelta: «ivamos, ni que hubiese regresado Cristóbal Colón de descubrir las Américas!» „99. Un periodista criticaba irónicamente, en la revista Acción Socialista, la dedicación del diario Nueva España en escudriñar cada recoveco de la vida de Belmonte:

Y en las columnas de España Nueva se ha dicho hasta la saciedad las veces que come Belmonte, cuándo duerme, en qué clase de cama, las lecturas que prefiere-en esto de la lectura no hay ironía-, el color del traje que usa, el de los calcetines, el de las camisetas, etc., y solamente ha faltado que se nos diga cuándo y cómo se lava ${ }^{70}$.

El periodista y escritor Juan José Cadenas (1872-1947) se lamentaba en las páginas del diario $A B C$ de que el presidente estadounidense Theodore Roosevelt (1858-1919), de visita en España, no hubiese "podido contemplar a la generación del desastre llorando de entusiasmo ante las valentías de Belmonte ${ }^{71}$. La propia existencia de Belmonte se había convertido en una manifestación de la regeneración de la nación. Sin embargo, también hubo periodistas que utilizaban la relevancia de Belmonte en la sociedad española para demostrar que el éxito de este torero era una prueba de la imposible regeneración del país. En 1917, Luis Antón del Olmet (1886-1923), en la publicación Blanco y Negro, frente a la enorme crisis política vivida por el país durante ese año, clamaba contra la actitud de los españoles, más preocupados por Belmonte que por el devenir de la nación, a los que acusaba de no haber cambiado desde 1898:

¿Renovación? ¿Leíste lo de Juan Belmonte? Mientras España atraviesa crisis tan grave y esta raza corre hacia el abismo, miles de seres aberrados cercaron á Belmonte, lo estrujaron contra su pecho y, locos de entusiasmo brutal, lo llevaron hasta su casa entre vítores. ¡Como el día siniestro de Santiago de Cuba! No hemos adelantado nada ${ }^{72}$.

68. "Se ha casado Belmonte». $A B C, 30$ de marzo de 1918, p. 16; «Sí que se ha casado Belmonte». El Liberal, 27 de abril de 1918, p. 2; «iSe casó Belmonte!», El Día, 27 de abril de 1918, p. 4.

69. $A B C, 25$ de agosto de 1918, pp. 7, 11.

70. BORN: «El sentido común reside en el toro». Acción Socialista, 18 de julio de 1914, p. 6.

71. Cadenas, Juan José: "Murmuraciones telefónicas». ABC, 7 de julio de 1914, p. 5.

72. Antón del Olmet, Luis: “Cartas a mis lares». Blanco y Negro, 14 de octubre de 1917, p. 34. 
Gracias a Belmonte, la imagen positiva del torero atravesó las fronteras, reafirmando así la figura del torero como una referencia mundial de la masculinidad española. El 5 de enero de 1925, la revista estadounidense Time le dedicaba su portada (Figura n ${ }^{\circ}$ 6). Los toreros, considerados en numerosas ocasiones por los extranjeros como un símbolo del retraso de España, eran nuevamente representados de forma positiva en los Estados Unidos en una publicación en la que solamente un español había aparecido en portada, el rey Alfonso XIII. Tres años antes, el director estadounidense Fred Niblo (1874-1948) había llevado a la gran pantalla la obra Sangre y Arena de Vicente Blasco Ibáñez (1867-1928) favoreciendo todavía más la difusión de la imagen del personaje del torero como elemento representativo de España.

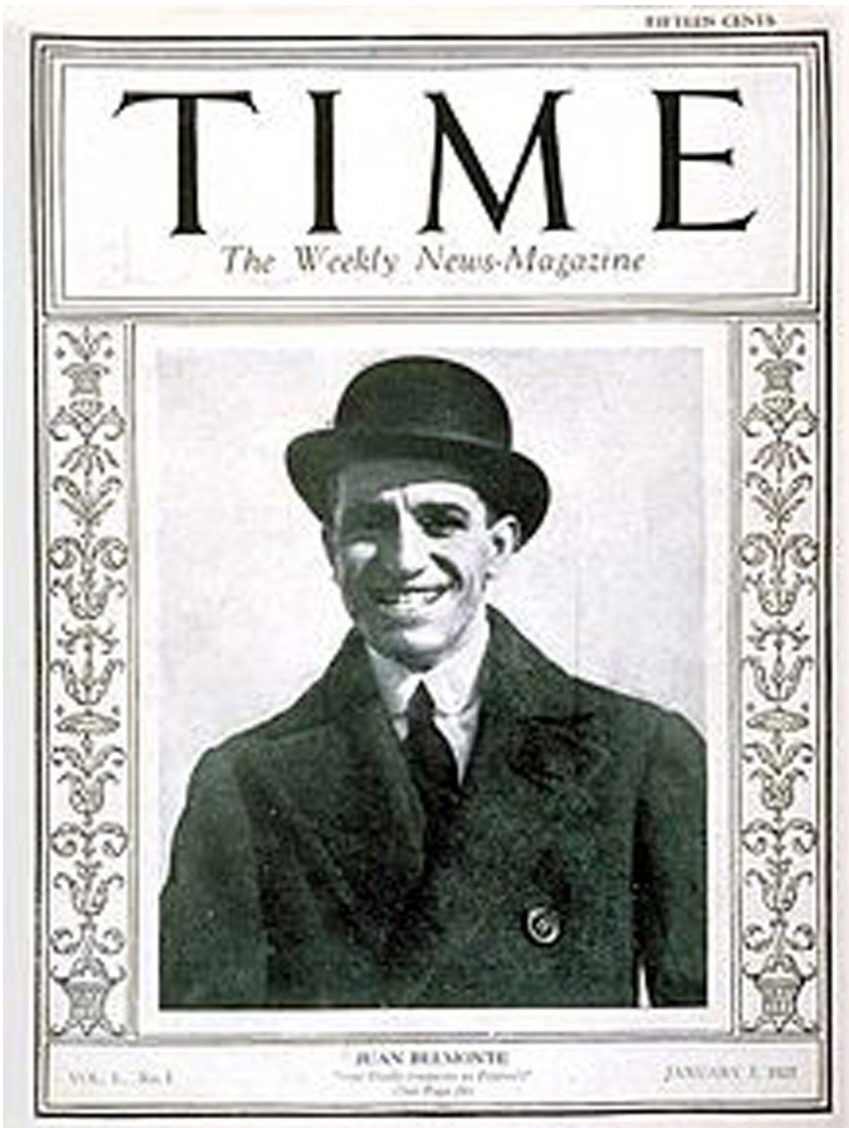

Figura $n^{\circ}$ 6: Belmonte en la portada de la revista Time ${ }^{73}$.

73. Time, 5 de enero de 1925. 
Belmonte participó en la década de 1920 en tres películas mudas: Frivolinas, La Malcasada y El Relicario. Estas diferentes actuaciones son una prueba más del potencial atractivo de Belmonte para las masas. En la película La Malcasada, su figura fue utilizada, junto a la de otros personajes importantes de la época, para proyectar una imagen positiva de las élites intelectuales y políticas de la sociedad española ${ }^{74}$ en un relato audiovisual que sirvió como instrumento para deslegitimar la posibilidad legal del divorcio, intentando aplacar un debate sobre su posible aplicación en España ${ }^{75}$, que ya había iniciado a principios de siglo Carmen De Burgos Seguí (1867-1932) ${ }^{76}$. El propio director de la cinta, Francisco Gómez Hidalgo (1886-1847), había escrito también una biografía sobre Juan Belmonte, publicada en 1914, en los inicios de su trayectoria profesional, y titulada Juan Belmonte, su vida y su arte ${ }^{77}$.

El desarrollo de la sociedad de masas contribuyó pues a idolatrar todavía más la figura de Belmonte. En su obra Death in the afternoon, publicada en 1932, Ernest Hemingway (1899-1961) subrayaba la revolución tauromáquica de Belmonte y le calificaba como el torero más grande de la historia ${ }^{78}$. Su jubilación definitiva, tras varias retiradas temporales, la primera entre 1921 y 1924, y la segunda entre 1927 y 1934, llegaría finalmente el 29 de septiembre de 1935. El torero continuó con su vida como ganadero hasta el día de su suicidio, el 8 de abril de 1962. Su muerte, como indica el testimonio del pintor Andrés Martínez de León (1895-1978), se produjo en una España en la que el fútbol ya había adelantado en popularidad a las corridas de toros:

Al entierro no fue mucha gente. A sus funerales, nadie. La Iglesia pasó por alto el suicidio. A muchos les pareció, el acto de Juan, una cobardía; a otros, un acto de entereza, digno de Belmonte. La gente joven no se emocionó: siguió hablando de fútbol ${ }^{79}$.

74. Marín Molina, Cristóbal: «La película La Malcasada como ejemplo de la proyección de la imagen estereotipada de los militares africanistas en los medios de comunicación", Revista Universitaria de Historia Militar, 6-11, 2017, pp. 217-238.

75. Caparrós Lera, José María: Arte y politica en el cine de la República (1931-1939). Barcelona: Universidad de Barcelona, 1981, p. 77.

76. Burgos Seguí, Carmen De: El divorcio en España. Madrid: M. Romero, 1904.

77. Gómez Hidalgo, Francisco: Juan Belmonte, su vida y su arte. Barcelona: Unión Editorial HispanoAmericana, 1914.

78. Hemingway, Ernest: Muerte en la tarde. Barcelona: Espasa, 2005 [1932].

79. Martínez de León, Andrés: Carta a José Pérez Gómez, 3 de agosto de 1962. En: Amorós, Andrés: "Hallan una carta que desvela las circunstancias de la muerte de Juan Belmonte». ABC, 3 de abril de 2015. En: http://www.abc.es/cultura/toros/20150403/abci-hallan-original-carta-desvela-201503272041.html, consultado el 29 de diciembre de 2019. 


\section{CONCLUSIONES}

La conceptualización de los fenómenos sociales de la degeneración y de la regeneración durante las primeras décadas del siglo XX fue determinada por el género. En un contexto cultural en el que los hombres eran asociados al progreso y las mujeres al atraso $^{80}$, la degeneración, relacionada con una mayor presencia de hombres afeminados y de mujeres masculinizadas según los cánones de género de la época, fue entendida como un proceso de feminización de los hombres españoles y la regeneración como el consiguiente restablecimiento de la virilidad de éstos. La regeneración de la nación española, como en otros países europeos, se traducía por la solidificación del statu quo de las relaciones y las identidades de género, y ésta se concretizó en España también a través de la corrida de toros, el símbolo nacional por excelencia.

La tauromaquia fue y sigue siendo un universo simbólico forjado en una visión androcéntrica del mundo en la que se glorifica la virilidad de los hombres españo1 es ${ }^{81}$. Esta forma de entender la lucha entre los seres humanos y los toros ha tenido como consecuencia la discriminación sistémica de las toreras desde el nacimiento de las corridas de toros modernas en España desde el siglo XVIII, cuando el espectáculo taurino nobiliario se convirtió progresivamente en una práctica que formaba parte de la cultura popular española. Si a mediados del siglo XIX, el torero se construyó discursivamente, como una imagen representativa de la masculinidad nacional en paralelo a la integración de la corrida de toros en el proceso de nacionalización ${ }^{82}$, la prohibición de 1908 puede ser considerada un hito en la nacionalización de la virilidad asociada con el espectáculo taurino.

La corrida de toros fue uno de los vectores de transmisión de la reafirmación de una determinada imagen de la masculinidad nacional frente a otras visiones alternativas de la masculinidad, propuestas principalmente por los sectores más progresistas de la sociedad, y frente a la multiplicación de la presencia en el espacio público de las mujeres emancipadas. Las representaciones producidas por el espectáculo taurino permitían asociar el hombre español con el hombre viril, diferenciándolo primero del conjunto de las mujeres gracias a la prohibición de 1908 y distinguiéndolo del hombre considerado afeminado deseoso de abolir la corrida de toros. Así pues, la práctica taurina, en el corazón de la construcción de la identidad española, fue utilizada como un medio para reforzar las identidades de género tradicionales. En el contexto de crisis

80. ARESTI, Nerea: Médicos, donjuanes y mujeres modernas: los ideales de feminidad y masculinidad en el primer tercio del siglo XX. Bilbao: Universidad de País Vasco, 2001, p. 23.

81. Puleo, Alicia: "El hilo de Ariadna: ecofeminismo, animales y crítica al androcentrismo». En: BarRios, Olga, Figueruelo, Ángela, López Teresa y Velayos, Carmen (eds.): Feminismo ecológico. Salamanca: Ediciones Universidad Salamanca, 2007, pp. 71-86.

82. Andreu, Xavier: El descubrimiento de España. Mito romántico e identidad nacional. Barcelona: Taurus, 2016, pp. 260-281. 
nacional desencadenado por el Desastre del 98, y el consiguiente miedo a la feminización de la nación, la corrida de toros no era un simple espectáculo representativo de la masculinidad española sino también un símbolo de resistencia y un medio de garantizar y reproducir la virilidad de las futuras generaciones de españoles. La españolidad podía seguir siendo asociada con la virilidad gracias a la corrida de toros, opuesta a las costumbres afeminadas de las otras naciones, y permitía a la nación protegerse de la decadencia, todavía más en una época en la que el país, sin fuerza económica ni militar, tuvo que mantener la neutralidad durante la Primera Guerra Mundial. De la misma manera que el soldado, las cualidades del deportista servían en este periodo a mantener la superioridad de los hombres y a luchar contra la degeneración de los cuerpos y de las naciones ${ }^{83}$. El hombre deportista era representado como el cuerpo masculino de la nación y la esperanza de la regeneración ${ }^{84}$.

Es en este contexto en el que la figura de Belmonte hizo que el personaje del torero fuese erigido por periodistas, escritores, artistas y filósofos, como un símbolo de la renovación de la masculinidad nacional. La amistad, pero sobre todo la admiración profesada por éstos hacia Belmonte, son una muestra de la importancia de la corrida de toros en la sociedad española de los años 1910. Si Francisco Montes (1804-1851) fue considerada una figura clave, como lo ha demostrado Xavier Andreu, en el proceso de nacionalización del estereotipo del torero durante el siglo XIX, fue entre otras cosas porque Montes era un hombre instruido, honesto, profesional, que tejió relaciones con miembros de las élites culturales y políticas ${ }^{85}$. De la misma manera que Montes logró contribuir a un cambio en la percepción del espectáculo, tanto dentro como fuera del país, convirtiéndose además en el protagonista absoluto del espectáculo, podemos considerar que el personaje de Juan Belmonte participó en un proceso de renacionalización de la corrida de toros, tras el progresivo alejamiento de las élites durante la Restauración que alcanzó su punto álgido tras el Desastre del 98, gracias a que Belmonte, un prototipo de soldado-ciudadano, era el representante de una masculinidad que sintetizaba la mezcla entre el modelo de masculinidad predominante entonces en España y otro más racional y consciente, reclamado por una parte de los círculos intelectuales. En los ruedos, Belmonte simbolizaba al soldado valiente, bravo y fuerte; en las calles, Belmonte encarnaba al ciudadano culto y humilde, aliado del progreso y de la civilización. Podemos decir que este icono de masas, adorado por su valiente forma de torear, admirado por alejarse de la figura embrutecida y bárbara del torero

83. Rauch, André: "Le défi sportif et l'expérience de la virilité». En: Corbin, Alain, Courtine, Jean-Jaques y Vigarello, Georges (dirs.): Histoire de la virilité, tomo 2. Paris: Seuil, 2011, p. 286.

84. URía, Jorge: «Imágenes de la masculinidad. El fútbol español en los años veinte», Ayer, 72, 2008, pp. 153-155.

85. Andreu, Xavier: op. cit., pp. 264-265. 
y al mismo tiempo cuestionado por su proximidad al ideal masculino del gentleman, permitió una resignificación de la imagen de la masculinidad nacional.

La Edad de Oro de las corridas de toros dotó de nuevo al espectáculo de cualidades tradicionalmente asociadas con la masculinidad, como el coraje, el vigor y la firmeza. La imagen del torero se revalorizó dentro de España pero también fuera, gracias principalmente a la figura de Juan Belmonte, un hombre que sustituyó la arrogancia, la ignorancia y la brutalidad, rasgos tradicionales del estereotipo del torero por la humildad, la instrucción y la elegancia. Este icono renovado de la masculinidad nacional permitió la reconciliación entre la Generación del 14 y la fiesta nacional borrando las huellas de la antipatía declarada por el Regeneracionismo hacia la tauromaquia. Los proyectos de regeneración que encontraron en el estereotipo del torero, los atributos necesarios para revitalizar la nación, provocaron la marginalización de los discursos que habían utilizado la corrida de toros como un ancla para demandar la transformación del modelo masculino nacional, proponiendo un prototipo de hombre español en el que el coraje estuviese al servicio de la inteligencia.

La originalidad de su estilo taurino, en el que predominaba la valentía frente el toro, fue sin duda uno de los elementos explicativos de su éxito, que unido a la llegada y el desarrollo de las tecnologías propias de la sociedad de masas, convirtieron a Belmonte en un icono masculino de la nación regenerada. Este artículo ha mostrado a través la trayectoria del torero Juan Belmonte las relaciones entre la corrida de toros, la nación y la masculinidad, en las primeras décadas del siglo XX, poniendo en evidencia que las representaciones de la masculinidad de este torero lograron dotar de prestigio a la práctica taurina, y por ende, impulsaron la reafirmación de un determinado modelo de masculinidad nacional basado en el estereotipo del torero. 